\title{
HEMATOMA RETROPERITONEAL ESPONTÂNEO
}

\section{SPONTANEOUS RETROPERITONEAL HEMATOMA}

\author{
Viviane Di Conti Figueirol ${ }^{1}$; Marco Antonio Salgueiro Júnior, ACBC-RJ ${ }^{2}$; \\ Marcelo Betim Paes Leme, TCBC-RJ ${ }^{3}$
}

\section{INTRODUÇÃO}

O hematoma retroperitoneal espontâneo é formado pelo extravasamento de sangue no compartimento retroperitoneal sem ocorrência de trauma externo, manobra endourológica ou endovascular. Sua etiologia é múltipla e clinicamente manifesta-se pela tríade de dor abdominal, massa palpável, hipovolemia ou anemia. O objetivo deste relato é divulgar e analisar um caso desta doença relativamente infreqüente, relacionada ao uso de ácido acetil-salicílico (AAS).

\section{RELATO DO CASO}

Paciente masculino, branco, 62 anos, com queixa de dor em hipocôndrio direito de forte intensidade que havia iniciado há quatro dias. O paciente encontrava-se acamado, com hemiparesia esquerda devido a acidente vascular cerebral ocorrido há dois meses. Ao exame físico, apresentava palidez cutâneo-mucosa acentuada, sopro sistólico $++/ 4+, \mathrm{FC}=72 \mathrm{bpm}, \mathrm{PA}=160 \times 100$ $\mathrm{mmHg}$. À palpação abdominal havia massa dolorosa em hipocôndrio e flanco direitos. Negava febre, náuseas, vômitos e trauma local. Referia estar em uso de AAS e pentoxifilina.

Foi realizada tomografia computadorizada de abdome que revelou massa de conteúdo heterogêneo, ocupando o espaço retroperitoneal à direita, medindo $20 \mathrm{~cm}$ de diâmetro axial, alças intestinais rechaçadas e deslocadas medialmente (Figura 1).

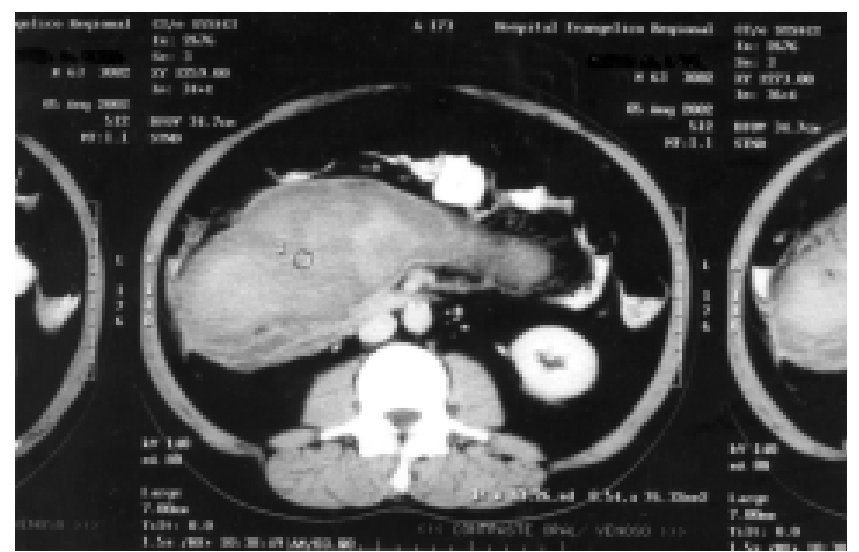

Figura 1 - TC de abdome demonstrando volumoso hematoma retroperitoneal à direita.
Para correção da anemia $(\mathrm{Ht}=24 \%)$ foi necessária transfusão de seis unidades de concentrado de hemácias.

Com base nestes achados foi indicada laparotomia exploradora. O inventário da cavidade evidenciou volumoso hematoma localizado no espaço retroperitoneal ocupando o hemiabdome direito. Realizou-se drenagem do mesmo através de abertura do mesocólon direito, que encontrava-se rechaçado anteriormente.

O paciente evoluiu bem e teve alta hospitalar no sexto dia de pós-operatório.

\section{DISCUSSÃO}

O hematoma retroperitoneal espontâneo caracterizase pela formação de coleção hemática no compartimento retroperitoneal de etiologia não traumática. As hemorragias de causa renal são as mais freqüentes e entre elas prevalecem as de origem tumoral ${ }^{1}$. Há também as de origem vascular e as relacionadas às doenças da glândula supra-renal ${ }^{2}$.

As discrasias sanguíneas são a base do hematoma retroperitoneal espontâneo que é denominado primário, por não existir doença pré-existente no rim e outras vísceras ${ }^{3}$. Entre as causas hematológicas de hematoma retroperitoneal incluem-se a púrpura trombocitopênica, hemofilia, policitemia e anticoagulação terapêutica, sendo, esta última, a causa mais freqüente deste grupo ${ }^{1,4}$.

A incidência de hemorragia retroperitoneal em pacientes em tratamento com anticoagulantes orais varia entre $0 \mathrm{e}$ $0,6 \%$. A administração de AAS parece não ter efeito na origem do hematoma retroperitoneal, mas pode, entretanto, perpetuar um sangramento. Desta forma, acredita-se que seja necessária a ocorrência de uma lesão prévia para justificar a formação de hematoma retroperitoneal em pacientes em uso de AAS ${ }^{5}$.

O caso relatado descreve um hematoma retroperitoneal espontâneo primário em paciente em uso de AAS, sem que se tenha detectado pela tomografia computadorizada e durante o ato operatório qualquer alteração que fosse responsável pelo sangramento.

O quadro clínico caracteriza-se pela tríade clássica, que consiste em dor abdominal, massa palpável em flanco e hipovolemia ou anemia ${ }^{1,3}$. O início dos sintomas pode ser insidioso, de vários dias de evolução, ou súbito, dependendo da velocidade do sangramento ${ }^{2}$.

\footnotetext{
1. Ex-Residente de Cirurgia Geral do Hospital São João Batista / UniFOA.

2. Residente de Cirurgia Geral do Hospital São João Batista / UniFOA.

3. Professor Assistente de Clínica Cirúrgica do Centro Universitário de Volta Redonda - UniFOA; Mestre em Gastroenterologia Cirúrgica pela UNIFESP - Escola Paulista de Medicina; Cirurgião do Hospital São João Batista / UniFOA.
} 
O diagnóstico do hematoma retroperitoneal espontâneo baseia-se nos dados clínicos e métodos de imagem, e, entre esses, a ultra-sonografia abdominal e a tomografia computadorizada de abdome são os que apresentam maior acurácia, não só no diagnóstico do hematoma, como também das doenças do rim, supra-renal e grandes vasos que poderiam dar origem ao sangramento ${ }^{1}$.

Em relação ao tratamento, há controvérsias entre os autores. Alguns preconizam a nefrectomia radical baseando- se na elevada incidência de malignidade oculta quando a origem é renal . Outros porém, tem preconizado tentar definir a etiologia no período pré-operatório para que o tratamento seja o mais conservador possível ${ }^{2,3}$.

Neste caso o paciente foi submetido a laparotomia exploradora que evidenciou volumoso hematoma retroperitoneal à direita, e que teve como tratamento sua drenagem. O diagnóstico estabelecido no período pré-operatório permitiu um tratamento mais conservador.

\begin{abstract}
We present a case of a spontaneous retroperitoneal hematoma in a 62 year-old man who was using acethylsalicylic acid (ASA). Spontaneous retroperitoneal hematoma is a rare, but potentially serious complication of anticoagulation therapy. Through literature revision, we have discussed the etiological aspects of this disease and the importance of obtaining the preoperative diagnosis for an appropriate and conservative operative treatment (Rev. Col. Bras. Cir. 2005; 32(1): 52-53).
\end{abstract}

Key words: Anticoagulants; hematoma; retroperitoneal space; salicylic acid.

\section{REFERÊNCIAS}

1. Reig Ruiz C, Morote Robles J, Saenz de Cabezon Marti J, et al. - Hematoma perirrenal espontaneo. Arch Esp Urol, 1992, 45(7):615-619.

2. Machuca Santa Cruz J, Julve Villata E, Galacho Bech A, et al. - Hematoma retroperitoneal espontâneo: nuestra experiência. Actas Urol Esp, 1999, 23(1):43-50.

3. Hidalgo L, Santos J, Jiménez N, et al. - Hematoma perirrenal espontaneo. Actas Urol Esp, 1981, 5(3):145-152.

4. Dabney A, Bastani B - Enoxaparin-associated severe retroperitoneal bleeding and abdominal compartment syndrome: a report of two cases. Intensive Care Med, 2001, 27(12):19541957.
5. Martin'Laborda Bergasa F, Vallejo Herrador J, Sanchez de la Muela Naverac P, et al. - Sindrome de Wunderlich por rotura de quiste simple en paciente tratada con acido acetil salicilico. Actas Urol Esp, 1998, 22(4):362-365.

Endereço para correspondencia:

Dr. Marcelo Betim Paes Leme

Rua Moacir de Paula Lobo, 19

27283-350 - Volta Redonda - RJ

E-mail:marcelo.leme@uol.com.br 